\title{
Catatan editor untuk edisi khusus tren metodologi: Paradigma dan metodologi psikologi sosial dalam kebudayaan non-WEIRD
}

\author{
Moh. Abdul Hakim ${ }^{1 *} \&$ Joevarian Hudiyana ${ }^{2}$ \\ ${ }^{1}$ Fakultas Psikologi, Universitas Negeri Sebelas Maret, Surakarta,Jawa Tengah \\ ${ }^{2}$ Fakultas Psikologi, Universitas Indonesia, Depok, Jawa Barat
}

\section{Salam sejahtera,}

Pada tahun 2015 silam, lebih dari 100 peneliti dari berbagai institusi di beberapa benua melakukan sebuah usaha replikasi penelitian besar-besaran. Tak kurang dari 100 eksperimen yang terbit dalam jurnal psikologi bereputasi diuji kembali untuk menemukan apakah memang betul hasil eksperimen sesuai dengan laporan asli. Ternyata, hanya $68 \%$ dari usaha replikasi itu yang berhasil menemukan bukti signifikan secara statistik (Open Science Collaboration, 2015). Masalah yang dikemukakan oleh komunitas Open Science Collaboration ini menggegerkan ilmu psikologi, tak terkecuali psikologi sosial. Sejak munculnya isu krisis replikasi ini, berbagai temuan-mulai dari yang klasik sampai yang kontemporer dalam bidang psikologi-dipertanyakan kembali keabsahannya.

Beberapa tahun kemudian, pakar neurosains kognitif dan advokat sains terbuka Christopher D. Chambers dari Cardiff University mempublikasikan sebuah buku yang membahas masalah fundamental dalam praktik ilmiah di psikologi. Dalam buku yang ia beri judul "The 7 Deadly Sins of Psychology" (7Dosa Besar Psikologi), ia memaparkan sejumlah isu dimana metodologi merupakan salah satu isu yang bermasalah dalam psikologi (Chambers, 2019). Analisis statistik dan penentuan metodologi dalam riset-riset psikologi dianggap terlalu fleksibel sehingga rentan untuk dimani pulasi oleh peneliti. Tidak kalah pentingnya dan konsisten dengan temuan Open Science Collaboration, ilmu psikologi juga dianggap tidak reliabel. Temuan-temuan penting bisa tidak konsisten ketika diuji kembali dengan metode yang sama.

Masalah pada reliabilitas temuan seperti itu bisa diatribusikan ke berbagai faktor. Pertama, psikologi belum membudayakan replikasi. Padahal, disiplin ilmu al am seperti fisi ka senantiasa berusaha mereplikasi temuan-temuan laboratorium mereka (Franklin, 2018). Kedua, adalah masalah fraud serta pelaporan metodologi atau analisisyang terlal u fleksibel sebagaimana dikemukakan Chambers (2019). Selain kedua alasan tersebut, ada satu alasan lain yang nampaknya jarang dibahas-bahwa ada faktor kebudayaan atau kontekstual yang menye-babkan kondisi studi asli dan studi berikutnya mengalami perbedaan. Alasan ini dikemukakan oleh Stroebe dan
Strack (2014) dalam artikel mereka yang isinya mengemukakan bahwa replikasi dengan temuan sama persis itu sangat sulit terjadi.

Faktor perbedaan budaya adalah isu yang substansial dan perlu diperhatikan dalam ilmu psikologi. Ini sudah lama ditekankan oleh Henrich, Heine, dan Norenzayan (2010) dalam artikel mereka yang berjudul "The weirdest people in the world?". Menurut mereka, banyak (jika tidak dibilang mayoritas) riset psikologi dilakukan di komunitas atau negara WEIRD (Western-kebudayaan barat; Educated-sampel mahasiswa atau kaum terdidik; Industrialized -negara industri maju; Rich-kalangan ekonomi menengah ke atas; dan Democratic-negara demokratik). Dengan kata lain, teori-teori yang dihasilkan dari riset-riset psikologi hanya terfokus pada kebudayaan WEIRD seperti Amerika Serikat dan Eropa Barat, tetapi mengabaikan kontekskonteks budaya lainnya. Sehingga, usaha generalisasi suatu teori tanpa memahami konteks lokal dari tiap kebudayaan non-WEIRD bisa menghasilkan temuan yang tidak konsisten.

Menyadari betapa fundamentalnya isu kebudayaan ini, Jurnal Psikologi Sosial (JPS) mengeluarkan isu khusus tentang perspektif dan isu metodologi dalam psikologi sosial. Dalamisukhusus ini, JPS mempublikasikan naskah-naskah yang mengevaluasi perspektif atau paradigma yang muncul dari kebudayaan atau masyarakat WEIRD. Dalam naskah yang berjudul "Social neuroscience: Pendekatan multilevel integratif dalam penelitian psikologi sosial", Galang Lufityanto berusaha mengulas potensi dari perspektif neurosains kognitifuntuk psikologi sosial dalam konteks manusia Indonesia. Artikel ini sangat penting karena perspektif biologis seperti neurosains kognitif perlu direplikasi di berbagai konteks masyarakat berbeda (Fischer \& Poortinga, 2018) agar terhindar dari generalisasi yang terlalu cepat.

Sementara dalam naskah yang berjudul "Epistemological violence, essentialization dan tantangan etik dalam penelitian psikologi sosial", Monica Eviandaru Madyaningrum berusaha mendiskusikan isu etika dalam riset psikologi sosial. Seringkali, psikologi sosial mengadopsi pandangan etika yang muncul dari kebudayaan seperti Amerika Serikat dimana etika prosedural yang terfokus pada individu menjadi tolak ukurnya. Padahal, etika juga 
mencakup kerangka berpikir dan relasi kuasa yang terjadi dalam masyarakat. Naskah ini mengajak kita untuk keluar dari isu etika individu menjadi isu etika dalam relasi antar elemen masyarakat, sehingga lebih sesuai dengan konteks masyarakat Indonesia.

Isu khusus ini tidak hanya terfokus pada persoalan paradigma epistemik dan etika dalam psikologi sosial. Beberapa naskah berikutnya membahas tentang potensi penggunaan metode alternatif untuk riset-riset psikologi sosial. Andrian Liem dan Brian J. Hall, dalam naskah mereka yang berjudul "Respondent-driven sampling (RDS) method: Introduction and its potential use for social psychology research", membahas potensi metode pencarian sampel (sampling) yang lebih superior daripada metode non-probabilitas lain tetapi juga lebih mungkin dilakukan dibandingkan metode random sampling. Dalam metode respondent-driven sampling (RDS), peneliti merekrut partisipan berdasarkan struktur jejaring atau rasa saling percaya antar partisipan. Mengingat masyarakat Indonesia beroperasi berdasarkan struktur relasi dan rasa saling percaya (Hopner \& Liu, in press), metode RDS ini sangat menjanjikan untuk diterapkan. Bukan hanya karena kemudahan dalam pengambilan data, namun juga karena potensinya untuk lebih mampu menggeneralisasi temuan ke dalam populasi yang diteliti.

Tidak kalah menariknya adalah naskah yang ditulis oleh Tsana Afrani dan para koleganya dengan judul "Apakah intervensi prasangka lewatmedia bisa mengurangi prasangka implisit terhadap orang dengan HIV/AIDS? Eksperimen menggunakan implicit association test (IAT)." Dalam beberapa tahun terakhir, IAT atau tes asosiasi implisit menjadi alat ukur prasangka implisit yang dianggap kontroversial (Jost, 2019; Singal, 2017). Intervensi berbasis prasangka implisit juga menjadi sasaran kritik. Maka dari itu, penting untuk menguji IAT dalam konteks intervensi di berbagai konteks seperti di kebudayaan non-WEIRD. Ditemukan bahwa prasangka implisit tidak berubah setelah partisipan ikut serta dalam intervensi prasangka lewat media. Ini semakin mempertebal daftar kritik terhadap IAT.

Naskah berikutnya membahas potensi metode kualitatif yang jarang digunakan dalam psikologi sosial, yaitu metode historis-komparatif. Dalam naskah yang berjudul "Menggunakan metode historis komparatif dalam penelitian psikologi", Nugraha Arif Karyanta, Suryanto, dan Wiwin Hendriani menjelaskan bahwa data-data seperti dokumen bersejarah, catatan sejarah, bahkan dokumen sipil yang masih berlangsung bisa digunakan untuk menjelaskan proses psikologis yang terjadi pada suatu konteks masyarakat. Metode ini berpotensi untuk mengeksplorasi bagaimana temuantemuan psikologi sosial yang seringkali muncul dari kebudayaan WEIRD bisa relevan atau tidak relevan dengan perkembangan sejarah, kebijakan sosial, dan hukum yang ada pada masyarakat non-WEIRD seperti masyarakat Indonesia.
Sementara itu Retno Hanggarani Ninin dan kolega-koleganya menekankan pentingnya asesmen psikologi dalam situasi alamiah. Dalam naskah yang berjudul "Psikoetnografi sebagai metoda asesmen psikologi komunitas", mereka membahas bahwa seringkali asesmen psikologis mencerabut individu dari situasi ekologis alami mereka. Padahal, individu tidak terlepas dari struktur sosial dan budaya yang ia alami sehari-hari. Dalam naskah ini, para penulis juga memberikan contoh bagaimana asesmen psikoetnografi bisa dilakukan.

Membahas perbedaan dan kesetaraan antar budaya, tentu juga sulit dilepaskan dari isu kesetaraan lintas budaya dari alat ukur psikologis. Dalam isu khusus ini, JPS mempublikasikan dua naskah validasi alat ukur. Kedua al at ukur ini dinilai penting dan relevan untuk diadaptasi dan divalidasi pada konteks Indonesia. Dalam naskah "Adaptasi alat ukur Munroe Multicultural Attitude Scale Questionnaire versi Indonesia", Intan Permatasari dan kolega-kol eganya mempertanyakan validasi alat ukur sikap multikultural karena pada budaya Indonesia, sikap multikultural lebih prevalen pada relasi antar etnis sementara di budaya Amerika Serikat (budaya asal alat ukurnya), sikap multikultural lebih terfokus pada warna kulit. Sementara pada naskah "Adaptasi dan properti psikometrik skala kontrol diri ringkas versi Indonesia", Haykal Hafizul Arifin dan Mirra Noor Milla berusaha mengadaptasi dan menemukan validitas konstruk dan validitas diskriminan dari alat ukur kontrol diri. Ada banyak struktur dimensi dari alat ukur kontrol diri dalam riset-riset sebelumnya. Para penulis menguï struktur dimensi mana yang paling cocok untuk konteks Indonesia.

Akhir kata, izinkanlah kami berterima kasih kepada para reviewer yang telah memberikan masukan kepada naskah-naskah di edisi khusus ini, mulai dari awal sampai naskah siap dipublikasikan. Kami berharap edisi khusus ini bisa menjadi pemantik diskusi-diskusi saintifik lanjutan tentang ragam perspektif dan isu metodologi di psikologi sosial, khususnya untuk konteks kebudayaan non-WEIRD seperti Indonesia. Tidak hanya itu, kami juga berharap bahwa edisi khusus ini bisa menjadi pedoman atau acuan bagi penggunaan berbagai metode seperti sampling RDS, alat ukur IAT, asesmen psikoetnografi, dan riset historis komparatif. Kami juga berharap edisi khusus ini menstimulasi riset lanjutan dengan paradigma social neuroscience dan paradigma etika yang lebih luas dari sekedar analisis etika prosedural.

Moh. Abdul Hakim adalah editor tamu JPS untuk Edisi Khusus Isu Metodologi Terkini Psikologi Sosial Indonesia. Sementara Joevarian Hudiyana adalah managing editor untuk JPS. 


\section{Daftar Pustaka}

Chambers, C. (2019). The Seven Deadly Sins of Psychology: A Manifesto for Reforming the Culture of Scientific Practice. Princeton University Press.

Fischer, R., \& Poortinga, Y. H. (2018). Addressing methodological challenges in culturecomparative research. Journal of CrossCultural Psychology, 49(5), 691-712. https://doi.org/10.1177/002202211773808 6

Franklin, A. (2018). Is it the 'same' result: Replication in physics. Morgan \& Claypool Publishers.

Henrich, J., Heine, S. J., \& Norenzayan, A. (2010). The weirdest people in the world?. Behavioral and brain sciences, 33(2-3), 61-83. https://doi.org/10.1017/S0140525X099915 2X

Hopner, V., \& Liu, J. H. (in-press). Relational ethics and epistemology: The case for complementary first principles in psy chology. Theory and Psychology.

Jost, J. T. (2019). The IAT is dead, long live the IAT: Context-sensitive measures of implicit attitudes are indispensable to social and political psychology. Current Directions in Psychological Science, 28(1), 10-19. https://doi.org/10.1177/096372141879730 9

Open Science Collaboration. (2015). Estimating the reproducibility of psychological science. Science, 349 (6251). doi: $10.1126 /$ science.aac 4716

Singal, J. (2017). Psychology's favorite tool for measuring racism isn't up to the job. New York Magazine.

Stroebe, W., \& Strack, F. (2014). The alleged crisis and the illusion of exact replication. Perspectives on Psychological Science, 9(1), 5971. 